\title{
The Effect of Channa striatus (Haruan) Extract on Pain and Wound Healing of Post-Lower Segment Caesarean Section Women
}

\author{
Siti Zubaidah Ab Wahab, ${ }^{1}$ Azidah Abdul Kadir, ${ }^{1}$ Nik Hazlina Nik Hussain, ${ }^{1}$ \\ Julia Omar, ${ }^{1}$ Rohaizan Yunus, ${ }^{1}$ Saringat Baie, ${ }^{2}$ Norhayati Mohd Noor, ${ }^{1}$ \\ Intan Idiana Hassan, ${ }^{3}$ Wan Haslindawani Wan Mahmood, ${ }^{1}$ Asrenee Abd Razak, \\ and Wan Zahanim Wan Yusoff ${ }^{4}$ \\ ${ }^{1}$ School of Medical Sciences, Universiti Sains Malaysia, Health Campus, 16150 Kubang Kerian, Kelantan, Malaysia
${ }^{2}$ School of Pharmaceutical Sciences, Universiti Sains Malaysia, 11800 Pulau Pinang, Malaysia
${ }^{3}$ School of Health Sciences, Universiti Sains Malaysia, Health Campus, 16150 Kubang Kerian, Kelantan, Malaysia
${ }^{4}$ Obstetrics \& Gynaecology Department, Hospital Raja Perempuan Zainab II, 15586 Kota Bharu, Kelantan, Malaysia
}

Correspondence should be addressed to Siti Zubaidah Ab Wahab; mczuey@gmail.com

Received 12 October 2014; Accepted 16 April 2015

Academic Editor: Shivananda Nayak

Copyright (C) 2015 Siti Zubaidah Ab Wahab et al. This is an open access article distributed under the Creative Commons Attribution License, which permits unrestricted use, distribution, and reproduction in any medium, provided the original work is properly cited.

Channa striatus has been consumed for decades as a remedy to promote wound healing by women during postpartum period. The objectives of this study were to compare postoperative pain, wound healing based on wound evaluation scale (WES), wound cosmetic appearance based on visual analogue scale (VAS) scores and patient satisfaction score (PSS), and safety profiles between $C$. striatus group and placebo group after six weeks of lower segment caesarean section (LSCS) delivery. A randomised, double-blind, placebo-controlled study was conducted. Subjects were randomised in a ratio of $1: 1$ into either the C. striatus group (500 mg daily) or placebo group (500 mg of maltodextrin daily). 76 subjects were successfully randomised, with 38 in the C. striatus group and 35 in the placebo group. There were no significant differences in postoperative pain $(p=0.814)$ and WES $(p=0.160)$ between the $C$. striatus and placebo groups. However, VAS and PSS in the C. striatus group were significantly better compared with the placebo group ( $p=0.014$ and $p<0.001$, resp.). The safety profiles showed no significant differences between the groups. In conclusion, six-week supplementation of $500 \mathrm{mg}$ of $C$. striatus extract showed marked differences in wound cosmetic appearance and patient's satisfaction and is safe for human consumption.

\section{Introduction}

Channa striatus is a fresh water snakehead fish, known in the Southeast Asian region for its protein and traditional remedy [1]. "Haruan" is the local name for C. striatus in Malaysia. It is a good source of health food amongst Asians because it contains high levels of amino acids and fatty acids [2]. C. striatus is also normally consumed by women postpartum to promote wound healing as well as reduce postoperative pain $[2,3]$.

Many scientific studies have unravelled the biomedical potential of the fish. This species is known for having the beneficial aspects of anti-inflammatory, antimicrobial, antinociceptive, and anticancer properties [2, 4]. Studies have shown that $C$. striatus has a good antinociceptive property that makes it suitable for reduction of postoperative pain in a manner comparable to morphine [3].

In addition to those properties, $C$. striatus has been proven to enhance the wound healing process in animal studies $[5,6]$. C. striatus extract contains biochemical components, such as amino acids and fatty acids, which are important for the synthesis of collagen fibres during wound healing $[1,2]$, particularly glycine. This species also has high contents of arachidonic acid and polyunsaturated fatty acids that can promote prostaglandin synthesis $[1,2]$, which plays a vital role in healing the wounds $[5,6]$. 
Thus, we undertook this study to assess the effects of C. striatus extract that may play possible roles or have great potential in wound healing and reducing postoperative pain in humans. This study was conducted to evaluate the effectiveness of C. striatus (Haruan) extract, as compared with a placebo, in terms of pain (postoperative pain), wound healing (wound evaluation scale), wound cosmetic appearance (visual analogue scale and patient's satisfaction score), and safety profiles (renal function test, liver function test, and full blood count) among post-lower segment caesarean section (LSCS) women.

\section{Methodology}

2.1. Study Design and Setting. This was a randomised, doubleblind, two-arm parallel comparative study of C. striatus extract versus a placebo amongst women who have undergone LSCS at the Universiti Sains Malaysia Hospital (HUSM), Kubang Kerian, Kelantan, and Raja Perempuan Zainab II Hospital (HRPZ II), Kota Bharu, Kelantan, from May 2011 to January 2013.

The inclusion criteria were women aged between 18 and 40 years who had undergone a LSCS with no present active medical, surgical, or gynaecological problems. The exclusion criteria included women who had taken any form of herbal extract in the previous three months before study entry and during the study period, had a history of drug or alcohol abuse, used fresh C. striatus during the study period, were taking warfarin or heparin, had been diagnosed with clinically relevant cardiovascular, gastrointestinal, hepatic, neurologic, endocrine, hematologic, or connective tissue disease or another major systemic disease that would influence the interpretation of the results, had a medical disorder requiring steroid or immunosuppressive therapy, had a chronic cough or other condition that may cause an increase in intra-abdominal pressure, and showed any congenital anterior abdominal wall defects.

The orally administered freeze-dried C. striatus extract was prepared by a GMP-certified laboratory at the School of Pharmaceutical Sciences, Universiti Sains Malaysia. Both the freeze-dried C. striatus extract and maltodextrin were available in capsules of $250 \mathrm{mg}$. The treatment group consumed $500 \mathrm{mg}$ of freeze-dried C. striatus extract, whereas the placebo group consumed $500 \mathrm{mg}$ of maltodextrin. The capsules were taken orally with water once daily and at any time of the day, with or without a meal.

Informed consent was obtained from the women 24-48 hours after the elective or emergency LSCS. The researchers ensured that the women were fully conscious and comfortable before informed consent was taken. Information on demographic data and past and concurrent medical history was obtained by interviewing the women. The researcher then performed physical examinations on the women.

On day 3 after the operation, the women were assessed for postoperative pain based on the numeric pain rating scale (NRS), wound healing based on the WES, wound cosmetic appearance based on the VAS, and patients' satisfaction regarding wound appearance based on patient satisfaction scores (PSS). The subjects were subsequently allocated into two groups using a computer-generated randomisation of numbers. The women were followed up at postoperative week 2, week 4, and week 6 for postoperative pain, wound healing, wound appearance, and patient satisfaction of the wound appearance. At every visit, any adverse event (AE) and concomitant medications were recorded. In addition, the women's compliance was measured at every visit using the number of capsules taken. Assessment of liver function, renal function, and full blood count was conducted at baseline and at the last visit (postoperative week 6) for measurement of the safety profiles. In this study, all the women underwent standard procedures for the LSCS and received standard postoperative pain management.

2.2. Outcome Measures. The outcome measures used in this study were 0-10 NRS [7] for postoperative pain, WES [8, 9] for wound healing, VAS [10] for wound cosmetic appearance, and PSS for overall patient's satisfaction with the appearance of the wound [11].

The WES was first developed by Hollander et al. [8] and later modified by Quinn and Wells [9], who proved that WES was a reliable tool in assessing surgical wounds. It consists of six items: presence or absence of wound discharge, edge inversion, step-off borders, contour irregularities, scar width more than $2 \mathrm{~mm}$, and overall cosmesis. Each of these categories was graded on a 0 -point (presence) or 1-point (absence) scale. A total cosmetic score was derived by adding the scores of the six categorical variables.

The VAS has been used globally in numerous cosmetic studies [12-14]. This scale consisted of a $100 \mathrm{~mm}$ line signifying the "worst scar" at the far right end and the "best scar" at the far left end of the line. The higher the score was, the better the cosmetic appearance was. Meanwhile, PSS was rated based on scores of 0 to 10 , with higher scores indicating better satisfaction and lower scores indicating poorer satisfaction. The PSS has been validated by Coulthard et al. [11] and Blondeel et al. [15] and revised by Amin et al. [16].

2.3. Sample Size Calculation. Sample size was calculated for all objectives of the study and the biggest sample size calculated was taken. The calculations were done using Power and Sample Size Calculation Software [17] for comparing two means between treatment group and placebo group. The biggest sample size calculated was yielded by wound healing assessment based on visual analogue scale. By using a standard deviation of 19 [9], taking the power of $90 \%$, detectable difference of 15 [9], and level of significance of 0.05 , the calculated sample size for each group was 35 . However after considering $10 \%$ dropout, the sample size for each group is 38 .

2.4. Statistical Analysis. Data were analyzed by SPSS version 20. In this study, the subjects were analyzed based on their assigned group, regardless of intervention attendance or compliance (intention-to-treat analysis). According to the protocol, the last-observation-carried-forward approach was used for patients who did not complete the study. Repeated measures for analysis of variance (RM ANOVA) 


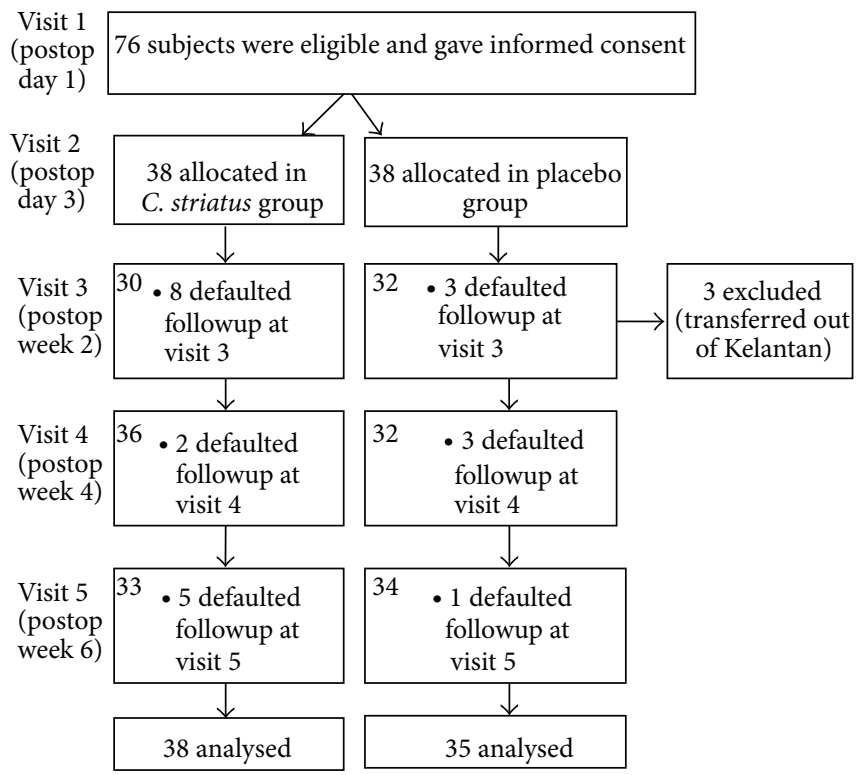

FIGURE 1: Flowchart of subject's progress throughout the study.

TABle 1: Demographic characteristic of the subjects.

\begin{tabular}{|c|c|c|c|c|c|}
\hline \multirow{2}{*}{ Demographic characteristic } & \multicolumn{2}{|c|}{ C. striatus $(n=38)$} & \multicolumn{2}{|c|}{ Placebo $(n=35)$} & \multirow{2}{*}{$p$ value } \\
\hline & Mean (SD) & $n(\%)$ & Mean (SD) & $n(\%)$ & \\
\hline Age & $28.11(4.93)$ & & $28.83(5.90)$ & & $0.570^{*}$ \\
\hline Parity & $2.42(1.69)$ & & $2.09(1.69)$ & & $0.399^{*}$ \\
\hline BMI & $23.06(3.50)$ & & $25.79(5.63)$ & & $0.014^{*}$ \\
\hline \multicolumn{6}{|l|}{ Types of LSCS } \\
\hline Elective & & $1(2.6)$ & & $5(14.3)$ & $0.875^{* *}$ \\
\hline Emergency & & $37(97.4)$ & & $30(85.7)$ & \\
\hline
\end{tabular}

${ }^{*}$ Determined by independent $t$-test.

${ }^{* *}$ Determined by simple logistic regression.

BMI = body mass index; LSCS $=$ lower segment caesarean section.

were used to compare postoperative pain scores and PSS at baseline, week 2, week 4, and week 6 . Body mass index (BMI) was added as a controlled variable for the analysis of covariance- (ANCOVA-) RM for WES and VAS. All $p$ values were reported as two-tailed results. The level of statistical significance was set at 0.05 .

2.5. Approval by the Ethical Committee. Ethical permission was obtained from the ethics research committee (Human) of the Universiti Sains Malaysia and with the permission of the Director of the HUSM on 31 December 2009 (Ref: USMKK/PPP/JEPeM [220.3.(04)]). For the HRPZ II, approval from the National Medical Research Register (NMRR) [Ref: NMRR-11-1018-10092] was obtained.

\section{Results}

Seventy-six subjects were successfully randomised into this study. The details are shown in Figure 1. Thirty-eight subjects were allocated to the $C$. striatus group, and thirty-eight subjects were allocated to the placebo group.
3.1. Baseline Characteristics of the Subjects. The demographic distribution and baseline clinical measurements of the subjects are shown in Tables 1 and 2. There was no significant difference detected between the C. striatus and placebo groups in terms of age, parity, and type of LSCS. However, there was a significant difference in terms of BMI between the $C$. striatus and placebo groups.

3.2. Intergroup Differences Based on Time (Postoperative Pain, WES, VAS, and PSS). Table 3 shows the intergroup differences of NRS, WES, VAS, and PSS based on time. The VAS and PSS scores were significantly higher in the C. striatus group than in the placebo group $(F=3.78, p=0.014$, and $F=9.06, p<0.001)$. This difference suggests that the $C$. striatus group had better wound appearance and higher PSS than the placebo group.

The C. striatus group showed a larger decrease in pain score over time compared with the placebo group, but this difference was not statistically significant $(F=0.32, p=$ 0.814 ). The same trends were observed for the WES, in which the scores were higher in the $C$. striatus group compared with 
TABLE 2: Clinical characteristics of study subjects at baseline (postoperative day 3).

\begin{tabular}{lccc}
\hline Clinical characteristic & $\begin{array}{c}\text { C. striatus } \\
(n=38) \\
\text { Mean (SD) }\end{array}$ & $\begin{array}{c}\text { Placebo } \\
(n=35) \\
\text { Mean (SD) }\end{array}$ & p value \\
\hline $\begin{array}{l}\text { Postoperative pain score } \\
\begin{array}{l}\text { Wound evaluation scale } \\
\text { (WES) }\end{array}\end{array}$ & $3.05(1.36)$ & $3.37(1.26)$ & 0.303 \\
$\begin{array}{l}\text { Visual analogue scale (VAS) } \\
\begin{array}{l}\text { Patient's satisfaction score } \\
\text { (PSS) }\end{array}\end{array}$ & $5.87(0.31)$ & $4.89(0.32)$ & 0.904 \\
\hline
\end{tabular}

$p$ values were determined using independent $t$-tests.

the placebo group, but this finding was also not statistically significant $(F=1.78, p=0.160)$.

3.3. Safety Profiles. There were no AEs reported by study subjects. All physical examinations and vital signs were within normal limits. Compliance to medication was $98-100 \%$. Tables 4 and 5 represent the lack of significant differences in all safety parameters between the C. striatus and placebo groups at baseline $(p>0.05)$ and the study endpoint (week 6; $p>0.05)$.

\section{Discussion}

In this study, we found that $C$. striatus extract could improve the cosmetic appearance of wounds and achieve high patient satisfaction regarding the cosmetic appearance of the wound. The VAS has been proven to have the highest sensitivity in detecting differences in the cosmetic appearance of a surgical wound [10]. The VAS has been used worldwide in cosmetics involving various types of wounds, such as reconstructive plastic surgery [13], laparoscopic pyeloplasty [14], scalp wounds [18], breast cancer surgery [19], breast augmentation surgery [12], and paediatric facial laceration wounds [20]. The VAS is usually used as an adjuvant assessment of other wound assessment tools, such as the patient and observer scar assessment scale, Vancouver scar scale, ASEPSIS, surgeonassessed Hollander scale, and the Manchester scar scale [19, $21,22]$. In the current study, VAS was used in adjuvant of WES.

There are a few plausible explanations behind these positive findings. The effectiveness of C. striatus as a wound cosmetic enhancer is thought to be influenced by the high level of specific amino acids, such as glycine, and fatty acids, such as arachidonic acid, in its makeup [5, 6]. These two compounds were believed to be involved in the promotion of wound healing by the initiation of a series of mechanisms involving the remodelling of collagen, reepithelialisation of the wound, and induction of wound contraction $[5,6]$. Glycine is important in the healing process when combined with arachidonic acid [2]. These acids are part of the major components of human skin collagen, which, when acting synergistically with other essential amino acids such as proline, alanine, arginine, isoleucine, phenylalanine, and serine, form a polypeptide that promotes tissue repairs and healing $[23,24]$.

C. striatus extract also contains arginine [2]. Barbul et al. [25] showed that arginine supplementation significantly enhanced the amount of collagen deposited into a standardised wound, as assessed by the larger amount of hydroxyproline present $(p<0.001)$. These effects also may have contributed to the improvement of the cosmetic appearance and PSS in the current study. Mustafa et al. (2012) [26] reported that C. striatus extract contains $3.43 \pm$ $0.28 \mathrm{mg} / 100 \mathrm{~mL}$ of zinc $(\mathrm{Zn})$. Administration of $\mathrm{Zn}$ orally could accelerate the healing process of surgical wounds [26]. This benefit could be because $\mathrm{Zn}$ plays important roles in protein synthesis and cell multiplication.

The interval of two weeks for followup in this study is the main factor for the insignificant results of pain assessment and wound assessment based on WES. For the postoperative pain score, women's pain levels were adequately controlled because they had received standard postoperative pain management. This management was evidenced by the mean scores of both groups for pain, which were approximately $2-3$, indicating that the pain levels were mild. Hence, for postoperative pain in this study, we conclude that the interval between assessment of pain and the use of concurrent analgesics influenced this study's insignificant results.

However, in an animal study conducted by Mat Jais et al. [3], the tail flick test (heat stimulus) and abdominal constriction test (chemical stimulus) showed that C. striatus extract does act as a potent analgesic agent alone and enhances other analgesics, such as morphine. It should be noted that the administration of these tests in that study was performed intraperitoneally, which differs from the oral administration of C. striatus extract in this study.

The same explanation goes for the insignificant result of the wound assessment based on the WES score. The first wound assessments were performed on postoperative day 3 , in which there was still the presence of significant inflammation. Within the first 14 days, it was assumed that the entire wound had healed and the process of scarring was in progress. The WES score yielded insignificant results because of the normal healing process that was missed to assess within the first two weeks.

Ideally, the best way to assess wound healing clinically is to monitor the wound as closely as possible each day. However, it is not feasible and practical to prolong the hospital stay of the women just for wound observation. Selfphotographs of the wound every day are another option, but the photograph might not be standardised in terms of lightning, position, and sharpness, which could lead to a range of biases. In this study, C. striatus extract did not present any AEs on the haematological profile. This finding was in line with a number of studies that proved natural products are safe to be consumed by humans [27-30].

There were several limitations identified in this study. For instance, a major limitation was the defaulter for the followup in this study. In addition, we struggled to make the duration of followup shorter to get better results. Future clinical trials could use a different cohort of surgical subjects, such as postappendectomy patients or those with bone fractures, to 
TABLE 3: Intergroup differences based on time for postoperative pain, WES, VAS, and PSS.

\begin{tabular}{|c|c|c|c|c|c|c|c|}
\hline Outcomes & Group & $\begin{array}{c}\text { Postop day } 3 \\
\text { Mean }(95 \% \text { CI })\end{array}$ & $\begin{array}{c}\text { Postop week } 2 \\
\text { Mean }(95 \% \text { CI) }\end{array}$ & $\begin{array}{c}\text { Postop week } 4 \\
\text { Mean (95\% CI) }\end{array}$ & $\begin{array}{c}\text { Postop week } 6 \\
\text { Mean }(95 \% \text { CI) }\end{array}$ & $F$-statistic & $p$ value \\
\hline \multirow{2}{*}{ Postoperative pain score } & C. striatus & $3.05(2.63,3.48)$ & $2.05(1.51,2.60)$ & $1.03(1.41,2.65)$ & $0.45(0.11,0.78)$ & \multirow{2}{*}{0.32} & \multirow{2}{*}{$0.814^{*}$} \\
\hline & Placebo & $3.37(2.93,3.81)$ & $2.17(1.60,2.74)$ & $1.46(1.06,1.85)$ & $0.66(0.31,1.00)$ & & \\
\hline \multirow{2}{*}{ Wound evaluation scale (WES) } & C. striatus & $4.89(4.79,5.00)$ & $5.47(5.14,5.79)$ & $5.36(4.95,5.77)$ & $5.43(5.05,5.80)$ & \multirow{2}{*}{1.78} & \multirow{2}{*}{$0.160^{* *}$} \\
\hline & Placebo & $4.89(4.78,5.00)$ & $5.44(5.10,5.78)$ & $4.93(4.49,5.36)$ & $5.17(4.78,5.56)$ & & \\
\hline \multirow{2}{*}{ Visual analogue scale (VAS) } & C. striatus & $5.86(5.74,5.97)$ & $5.86(5.46,6.25)$ & $6.85(6.41,7.28)$ & $7.24(6.72,7.76)$ & \multirow{2}{*}{3.78} & \multirow{2}{*}{$0.014^{* *}$} \\
\hline & Placebo & $5.87(5.75,6.00)$ & $5.67(5.26,6.08)$ & $6.05(5.60,6.51)$ & $6.71(6.17,7.26)$ & & \\
\hline \multirow{2}{*}{ Patient's satisfaction (PSS) } & C. striatus & $5.37(4.64,6.09)$ & $7.78(7.22,8.35)$ & $9.89(9.59,10.00)$ & $9.74(9.53,9.96)$ & \multirow{2}{*}{9.06} & \multirow{2}{*}{$<0.001^{*}$} \\
\hline & Placebo & $5.40(4.65,6.16)$ & $7.58(6.99,8.17)$ & $8.64(8.32,8.95)$ & $9.54(9.31,9.76)$ & & \\
\hline
\end{tabular}

${ }^{*}$ RM ANOVA was applied, followed by pairwise comparison with Bonferroni confidence interval adjustment. Assumption of normality, homogeneity of variances, and compound symmetry were checked and fulfilled.

** RM ANCOVA was applied, followed by pairwise comparison with Bonferroni confidence interval adjustment. Numerical covariate (BMI) was controlled. Assumption of normality, homogeneity of variances, and compound symmetry were checked and fulfilled.

TABLE 4: Baseline (postop day 3) safety parameters.

\begin{tabular}{lccc}
\hline Parameters & $\begin{array}{c}\text { C. striatus }(n=38) \\
\text { Mean }(\mathrm{SD})\end{array}$ & $\begin{array}{c}\text { Placebo }(n=35) \\
\text { Mean }(\mathrm{SD})\end{array}$ & $p$ value \\
\hline $\begin{array}{l}\text { Urea }(\mathrm{mmol} / \mathrm{L}) \\
\begin{array}{l}\text { Creatinine } \\
(\mu \mathrm{mol} / \mathrm{L})\end{array}\end{array}$ & $4.15(1.19)$ & $4.21(1.38)$ & 0.847 \\
$\begin{array}{l}\text { Total protein }(\mathrm{g} / \mathrm{L}) \\
\text { Albumin }(\mathrm{g} / \mathrm{L})\end{array}$ & $66.82(46.02)$ & $73.94(10.17)$ & 0.987 \\
$\begin{array}{l}\text { Aspartate } \\
\text { aminotransferase }\end{array}$ & $23.74(11.98)$ & $25.54(15.70)$ & 0.581 \\
$\begin{array}{l}\text { (U/L) } \\
\begin{array}{l}\text { Alanine } \\
\text { transaminase }\end{array}\end{array}$ & $15.29(7.34)$ & $15.94(9.52)$ & 0.543 \\
$(\mathrm{U} / \mathrm{L})$ & & $34.30(13.11)$ & 0.511 \\
$\begin{array}{l}\text { White blood cell } \\
\text { count }\left(\times 10^{9} / \mathrm{L}\right)\end{array}$ & $14.10(2.73)$ & $12.61(3.23)$ & 0.742 \\
$\begin{array}{l}\text { Haemoglobin }(\mathrm{g} / \mathrm{L}) \\
\text { Platelet }\left(\times 10^{9} / \mathrm{L}\right)\end{array}$ & $10.38(1.77)$ & $11.03(2.22)$ & 0.505 \\
\hline
\end{tabular}

$p$ values were determined using independent $t$-tests.

allow for closer daily monitoring of the wound and better determination of the percentage of wound healing. The trial of other formulations of the extract, such as cream or spray applications, for human wound healing would also be useful. Future works should further emphasize finding bioactive compounds and research on standardisation of the extract.

\section{Conclusion}

From the findings of this study, it can be concluded that the oral administration of C. striatus extract $500 \mathrm{mg}$ daily does have marked differences in terms of wound cosmetic appearance and patient satisfaction score towards the wound appearance. However, this extract does not show any significant reduction of postoperative pain and improvement of wound healing based on the WES. The oral administration of C. striatus extract at $500 \mathrm{mg}$ daily did not produce any AEs to the study subjects.
TABLE 5: Study endpoint (week 6) safety parameters.

\begin{tabular}{|c|c|c|c|}
\hline Parameters & $\begin{array}{c}\text { C. striatus }(n=38) \\
\text { Mean }(\mathrm{SD})\end{array}$ & $\begin{array}{c}\text { Placebo }(n=35) \\
\text { Mean }(S D)\end{array}$ & $p$ value \\
\hline Urea $(\mathrm{mmol} / \mathrm{L})$ & $4.48(1.21)$ & $4.34(1.18)$ & 0.130 \\
\hline $\begin{array}{l}\text { Creatinine } \\
(\mu \mathrm{mol} / \mathrm{L})\end{array}$ & $78.11(8.17)$ & $79.43(9.38)$ & 0.875 \\
\hline Total protein $(\mathrm{g} / \mathrm{L})$ & $80.14(24.25)$ & $84.65(26.34)$ & 0.214 \\
\hline Albumin $(\mathrm{g} / \mathrm{L})$ & $38.23(8.54)$ & $37.06(6.12)$ & 0.538 \\
\hline $\begin{array}{l}\text { Aspartate } \\
\text { aminotransferase } \\
(\mathrm{U} / \mathrm{L})\end{array}$ & $20.43(6.71)$ & $20.37(6.92)$ & 0.817 \\
\hline $\begin{array}{l}\text { Alanine } \\
\text { transaminase } \\
(\mathrm{U} / \mathrm{L})\end{array}$ & $17.87(8.79)$ & $17.57(16.58)$ & 0.896 \\
\hline $\begin{array}{l}\text { White blood cell } \\
\text { count }\left(\times 10^{9} / \mathrm{L}\right)\end{array}$ & $6.76(1.43)$ & $7.14(1.66)$ & 0.295 \\
\hline Haemoglobin $(\mathrm{g} / \mathrm{L})$ & $11.50(2.61)$ & $11.55(2.37)$ & 0.337 \\
\hline $\begin{array}{l}\text { Platelet count } \\
\left(\times 10^{9} / \mathrm{L}\right)\end{array}$ & $277.39(48.21)$ & $293.00(71.99)$ & 0.277 \\
\hline
\end{tabular}

\section{Conflict of Interests}

The authors declare that there is no conflict of interests regarding the publication of this paper.

\section{Acknowledgment}

This work was financially supported by the Research University Grant (1001/PPSP/812090), funded by Universiti Sains Malaysia.

\section{References}

[1] A. M. Mat Jais, "Pharmacognosy and pharmacology of Haruan (C. striatus), a medicinal fish with wound healing properties," Boletin Latinoamericano y del Caribe de Plantas Medicinales y Aromaticas, vol. 6, pp. 52-60, 2007. 
[2] M. A. M. Shafri and M. J. Abdul Manan, "Therapeutic potential of the haruan (Channa striatus): from food to medicinal uses," Malaysian Journal of Nutrition, vol. 18, no. 1, pp. 125-136, 2012.

[3] A. M. Mat Jais, Y. M. Dambisya, and T.-L. Lee, "Antinociceptive activity of Channa striatus (haruan) extracts in mice," Journal of Ethnopharmacology, vol. 57, no. 2, pp. 125-130, 1997.

[4] N. Y. T. Michelle, G. Shanti, and M. Y. Loqman, "Effect of orally administered C. striatus extract against experimentallyinduced osteoarthritis in rabbits," International Journal of Applied Research Veterinar Medicine, vol. 2, no. 3, pp. 171-175, 2004.

[5] S. H. Baie and K. A. Sheikh, "The wound healing properties of Channa striatus-cetrimide cream-tensile strength measurement," Journal of Ethnopharmacology, vol. 71, no. 1-2, pp. 93-100, 2000.

[6] S. H. Baie and K. A. Sheikh, "The wound healing properties of Channa striatus-cetrimide cream-wound contraction and glycosaminoglycan measurement," Journal of Ethnopharmacology, vol. 73, no. 1-2, pp. 15-30, 2000.

[7] M. McCaffrey and C. Pasero, Pain: Clinical Manual, Mosby, St. Louis, Mo, USA, 2nd edition, 1999.

[8] J. E. Hollander, A. J. Singer, S. Valentine, and M. C. Henry, "Wound registry: development and validation," Annals of Emergency Medicine, vol. 25, no. 5, pp. 675-685, 1995.

[9] J. V. Quinn and G. A. Wells, "An assessment of clinical wound evaluation scales," Academic Emergency Medicine, vol. 5, no. 6, pp. 583-586, 1998.

[10] J. V. Quinn, A. E. Drzewiecki, I. G. Stiell, and T. J. Elmslie, "Appearance scales to measure cosmetic outcomes of healed lacerations," American Journal of Emergency Medicine, vol. 13, no. 2, pp. 229-231, 1995.

[11] P. Coulthard, H. Worthington, M. Esposito, M. Elst, and O. J. Waes, "Tissue adhesives for closure of surgical incisions," Cochrane Database of Systematic Reviews, no. 2, Article ID CD004287, 2004.

[12] M. L. von Sperling, H. Høimyr, K. Finnerup, T. S. Jensen, and N. B. Finnerup, "Persistent pain and sensory changes following cosmetic breast augmentation," European Journal of Pain, vol. 15, no. 3, pp. 328-332, 2011.

[13] N. P. dos Santos, A. S. Barnabe, J. V. Fornari, and R. R. N. Ferraz, "Pain assessment in patients undergoing cosmetic or reconstructive plastic surgery," Revista Brasileira de Cirurgia Plastica, vol. 27, no. 2, pp. 190-194, 2012.

[14] C. Fiori, I. Morra, R. Bertolo, F. Mele, M. L. Chiarissi, and F. Porpiglia, "Standard vs mini-laparoscopic pyeloplasty: perioperative outcomes and cosmetic results," BJU International, vol. 111, no. 3, pp. E121-E126, 2013.

[15] P. N. V. Blondeel, J. W. Murphy, D. Debrosse et al., "Closure of long surgical incisions with a new formulation of 2octylcyanoacrylate tissue adhesive versus commercially available methods," American Journal of Surgery, vol. 188, no. 3, pp. 307-313, 2004.

[16] M. Amin, F. Glynn, and C. A. Timon, "Randomized trial of tissue adhesive vs staples in thyroidectomy integrating patient satisfaction and Manchester score," Otolaryngology_Head and Neck Surgery, vol. 140, no. 5, pp. 703-708, 2009.

[17] W. D. Dupont and W. Plummer, "PS power and sample size program available for free on the internet," Controlled Clinical Trials, vol. 18, no. 3, p. 274, 1997.

[18] A. N. G. A. Khan, P. S. Dayan, S. Miller, M. Rosen, and D. H. Rubin, "Cosmetic outcome of scalp wound closure with staples in the pediatric emergency department: a prospective, randomized trial," Pediatric Emergency Care, vol. 18, no. 3, pp. 171-173, 2002.

[19] Z.-T. Zhang, H.-W. Zhang, X.-D. Fang et al., "Cosmetic outcome and surgical site infection rates of antibacterial absorbable (Polyglactin 910) suture compared to Chinese silk suture in breast cancer surgery: a randomized pilot research," Chinese Medical Journal, vol. 124, no. 5, pp. 719-724, 2011.

[20] R. P. Luck, R. Flood, D. Eyal, J. Saludades, C. Hayes, and J. Gaughan, "Cosmetic outcomes of absorbable versus nonabsorbable sutures in pediatric facial lacerations," Pediatric Emergency Care, vol. 24, no. 3, pp. 137-142, 2008.

[21] T. L. Khoo, A. S. Halim, Z. Zakaria, A. Z. Mat Saad, L. Y. Wu, and H. Y. Lau, "A prospective, randomised, double-blinded trial to study the efficacy of topical tocotrienol in the prevention of hypertrophic scars," Journal of Plastic, Reconstructive and Aesthetic Surgery, vol. 64, no. 6, pp. e137-e145, 2011.

[22] Y. L. Yang, Y. Y. Xiang, L. P. Jin et al., "Closure of skin incision after thyroidectomy through a supraclavicular approach: a comparison between tissue adhesive and staples," Scandinavian Journal of Surgery, vol. 102, no. 4, pp. 234-240, 2013.

[23] M. B. Witte and A. Barbul, "Role of nitric oxide in wound repair," American Journal of Surgery, vol. 183, no. 4, pp. 406-412, 2002.

[24] B. C. Katzung, Basic and Clinical Pharmacology, Appleton \& Lange, Norwalk, Conn, USA, 6th edition, 1995.

[25] A. Barbul, S. A. Lazarou, D. T. Efron, H. L. Wasserkrug, and G. Efron, "Arginine enhances wound healing and lymphocyte immune responses in humans," Surgery, vol. 108, no. 2, pp. 331337, 1990.

[26] A. Mustafa, M. A. Widodo, and Y. Kristiano, "Albumin and zinc content of snakehead fish (Channa striata) extract and its role in health," International Journal of Science and Technology, vol. 1, no. 2, pp. 1-8, 2012.

[27] N. S. Al-Waili, "Intravenous and intrapulmonary administration of honey solution to healthy sheep: effects on blood sugar, renal and liver function tests, bone marrow function, lipid profile, and carbon tetrachloride-induced liver injury," Journal of Medicinal Food, vol. 6, no. 3, pp. 231-247, 2003.

[28] Y. L. Husniati, N. H. N. Hazlina, A. K. Azidah et al., "Safety of honey in postmenopausal women," International Medical Journal, vol. 20, no. 1, pp. 25-28, 2013.

[29] G. Belcaro, M. R. Cesarone, M. Dugall et al., "Efficacy and safety of Meriva, a curcumin-phosphatidylcholine complex, during extended administration in osteoarthritis patients," Alternative Medicine Review, vol. 15, no. 4, pp. 337-344, 2010.

[30] A. George, D. Wilson, A. Abas, and M. Evans, "Safety and efficacy of a Labisia pumila var alata water extract on sexual well being and lipid profile of pre- and postmenopausal women: a randomized double-blind pilot study," African Journal of Biotechnology, vol. 13, no. 6, pp. 768-777, 2014. 


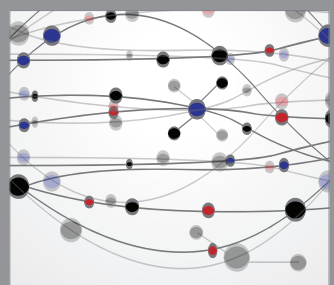

The Scientific World Journal
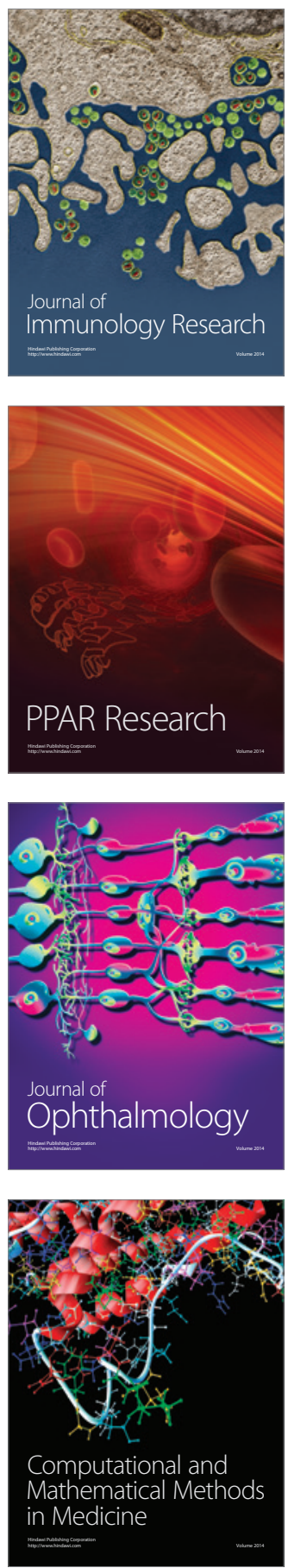

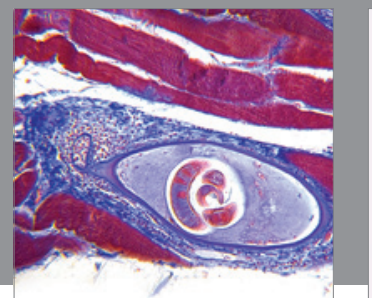

Gastroenterology

Research and Practice
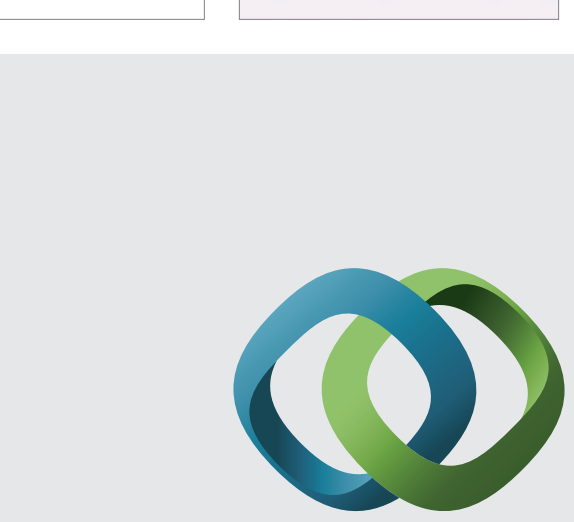

\section{Hindawi}

Submit your manuscripts at

http://www.hindawi.com
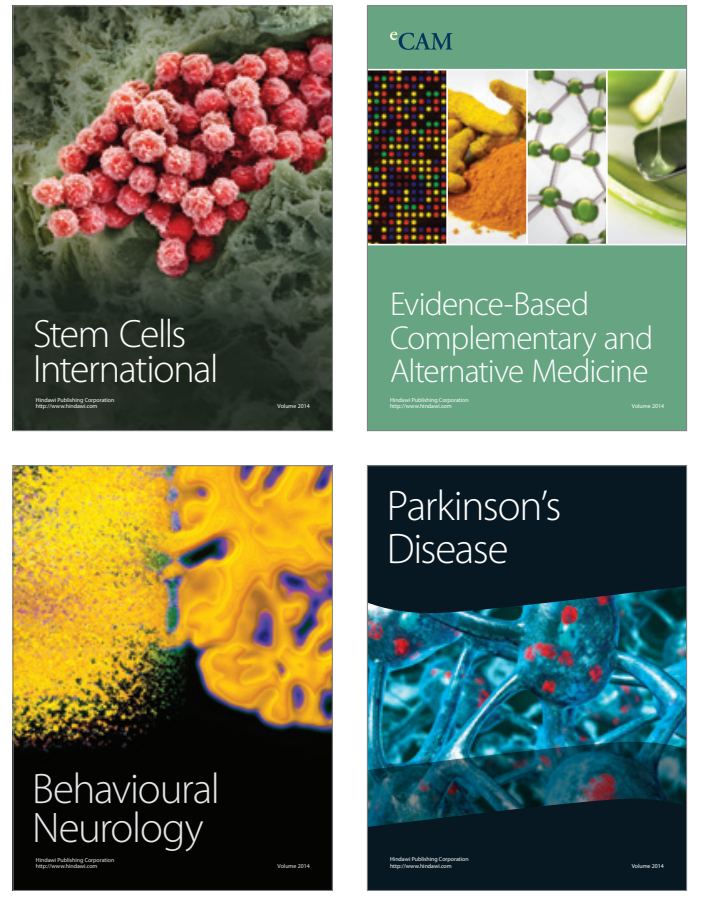
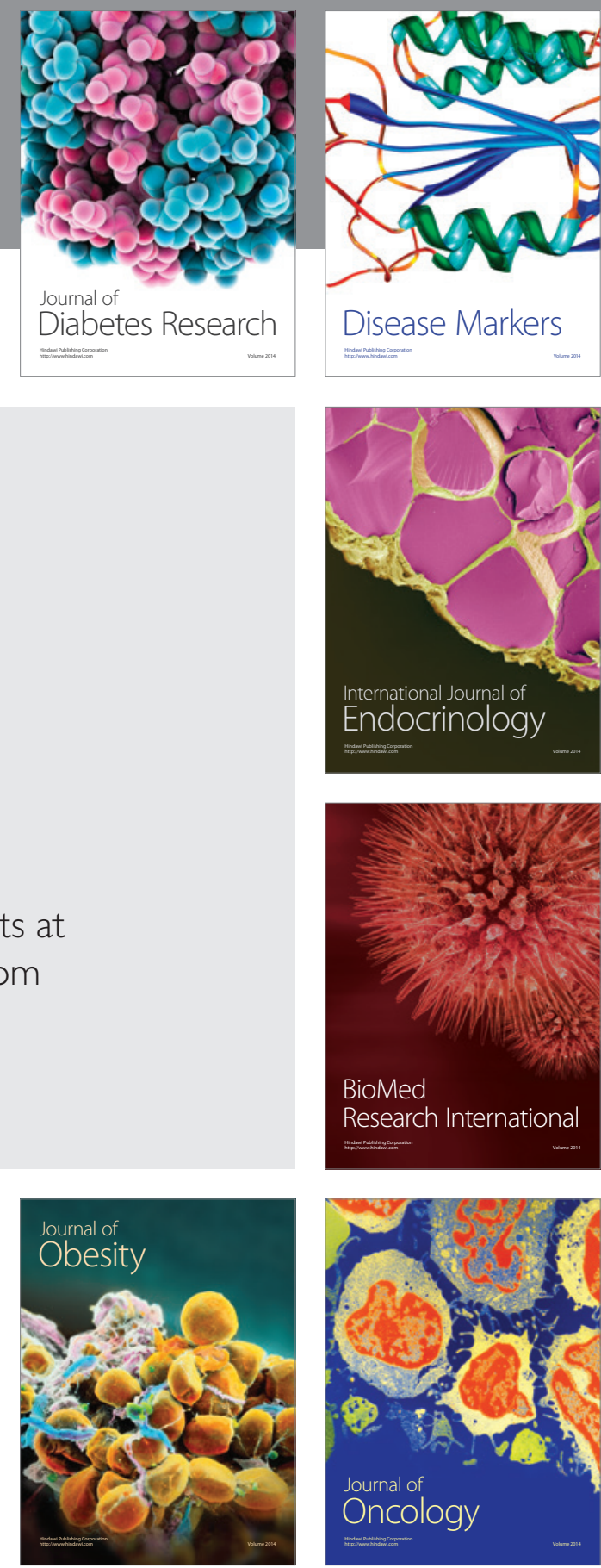

Disease Markers
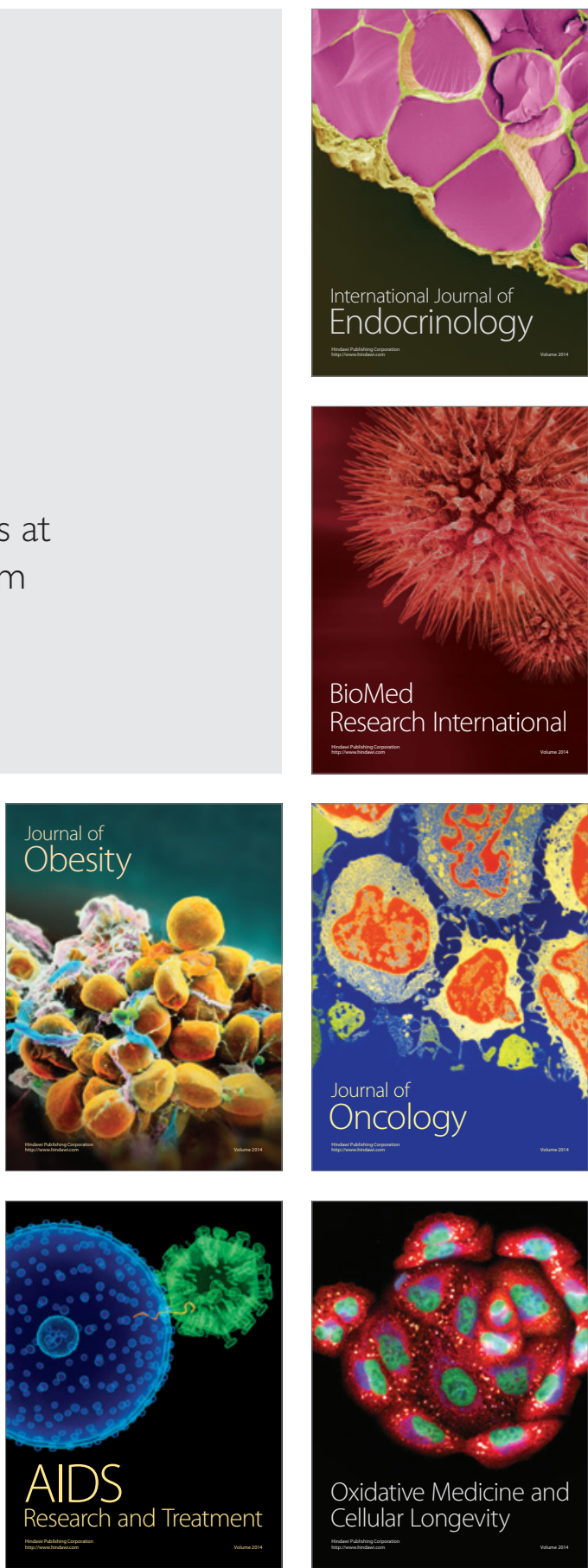